\title{
DON QUIJOTE Y EL PROBLEMA DE LA REALIDAD
}

¿En qué circunstancias pensamos nosotros las cosas como reales? William James hace esta pregunta en uno de los más notables capítulos de sus Principios de Psicología ${ }^{1}$ y parte de este punto para desarrollar su teoría de los distintos órdenes de realidad. Así encuentra que cualquier objeto que se_presenta_sin contradicción es inmediatamente aceptado como realidad absoluta. Y una cosa pensada no puede ser contradicha por otra, a no ser que comience una disputa diciendo ésta algo inadmisible acerca de la primera. Cuando sucede esto, la mente tiene que elegir una de las dos. Se cree en una proposición, ya sea atributiva o existencial, en virtud del hecho mismo de ser concebida, a no ser que choque con otras proposiciones diversas en las que creamos al mismo tiempo y que afirmen que los términos de estas últimas son los mismos que los términos de las otras. La verdadera distinción entre lo real-y-lo_irreal, toda la psicología del creer, del no creer y de la duda, según William James, se apoya siempre en dos hechos mentales: primero, que nosotros estamos expuestos a pensar de modo diferente el mismo objeto; y segundo, que una vez que hemos hecho esto, podemos ya saber cuál es_la_manera de pensar que aceptamos, y cuál es la que rechazamos. El origen y fuente de toda realidad, bien sea desde un punto de vista absoluto o bien sea desde un punto de vista práctico, es, por lo tanto, subjetivo, se encuentra en nosotros mismos. Por consiguiente, existe probablémente un número infinito de órdenes diferentes de realidad, cada uno con su propio, especial y distinto estilo de existencia, llamados por James "sub-universos". Entre ellos está el mundo de los sentidos o de las "cosas" físicas, tal como las experimenta el sentido comün, que es la realidad por excelencia; el mundo de la ciencia; el mundo de las relaciones ideales; de los "idola tribu"; los mundos sobrenaturales, tales como el cielo y el infierno cristianos; los numerosos mundos de las opiniones individuales; $y$, finalmente, los mundos de la franca locura y de la extravagancia, también infinitamente numerosos. Cada objeto que pensamos puede referirse cuando menos a uno $u$ otro mundo de ésta $\mathbf{u}$ otra parecida lista. Cada mundo, mientras que se atiende a él, es real de acuerdo con su propia hechura, y cualquiera relacion con nuestra mente basta para hacer real un objeto, siempre que no se de otra retación mas fuerte con la cual tropiece.

Hasta aquí William James. Este no es el lugar de investigar de qué manera la mente otorga una dimensión de realidad a uno de esos sub-universos

1 William James, Principles of Psychology, Henry Holt, New York, 1927; vol. II, págs. 287 sigs. 
y lo separa de los otros; ni tampoco de averiguar cómo ocurre la transición de un dominio de la realidad a otro; ni, finalmente, tampoco de estudiar cuáles son los rasgos de conciencia que caracterizan las diferentes provincias o subuniversos de realidad. ${ }^{2}$ Las pocas frases citadas de William James delimitan nuestro propósito de analizar el problema de la realidad en el Don Quijote de Cervantes. La tesis que nosotros queremos presentar es la de que la novela de Cervantes trata sistemáticamente del problema mismo de las realidades múltiples, tal y como lo presenta William james, y que muchos aspectos de las aventuras de Don Quijote son variaciones, cuidadosamente elaboradas, del tema principal, esto es, de qué modo experimentamos la realidad. Este problema tiene muchos aspectos, dialécticamente entrelazados. Está el mundo de la locura de Don Quijote, el mundo de la caballería, un sub-universo de realidad incompatible con la realidad primordial de la vida diaria, en la cual se desenvuelven con sencillez el barbero, el sacerdote, el ama de llaves y la sobrina, tomando esto como cosa obvia, sin ningún género de duda. ¿Cómo puede ser que Don Quijote otorgue una dimensión de realidad a su subuniverso de fantasía, si éste choca con la realidad principal, en la que no hay castillos, ni ejércitos, ni gigantes, sino solamente posadas, rebaños de ovejas y molinos de viento? ¿Cómo es posible que el mundo privado de Don Quijote no sea un mundo lleno de solipsismos y que haya otras mentes dentro de esta realidad, que no existen sólo como objetos de la experiencia de Don Quijote, sino que comparten con él, cuando menos hasta cierto punto, la creencia en su realidad efectiva o potencial? Y, finalmente, tampoco el sub-universo de la locura de Don Quijote, ni la realidad primordial de los sentidos, como William James lo llama, en la cual nosotros, Sanchos, vivimos nuestra vida cotidiana, resultan ser tan monolíticos como parecen. Ambos tienen algo así como entronques de experiencias que trascienden $\mathrm{los}$ sub-universos aceptados tanto por Don Quijote como por Sancho Panza, y que se refieren a otros reinos de realidad no compatibles con ninguno de los dos. Hay ruidos nocturnos enigmáticos y aterradores, hay muerte y sueños; visión y arte; profecía y ciencia. ¿Cómo es que Don Quijote y Sancho logran mantener con éxito la creencia en la realidad del sub-universo cerrado que han escogido como base de su vida a pesar de las muchas irrupciones de experiencias que los trascienden?

Primero, fijémonos en el mundo de la caballería de Don Quijote. Sin ninguna duda, éste es un sub-universo cerrado, y también sin duda alguna Don Quijote le concede la dimensión de realidad. Una y otra vez el ingenioso caballero rechaza cualquier duda de parte de los ajenos al mundo de la caballería, respecto de que los héroes de los libros de caballerías hayan jamás existido, y de que sus aventuras ocurrieran tal como están descritas en dichos libros. Don Quijote tiene buenos argumentos que brindar. La institu-

2 Un primer ensayo de análisis de estos problemas aparece en mi trabajo "On multiple realities", Philosophy and Phenomenological Research, vol. V., junio, 1945, págs. 563-567. 
ción de la caballería andante, le explica al canónigo de Toledo (pp. 328-31), , está universalmente reconocida y autorizada. La historia de Fierabrás tuvo lugar en tiempo de Carlomagno, las hazañas del Rey Arturo están registradas en las Historias y anales de Inglaterra; en la Armería Real de Madrid puede verse el corno de Rolando, aun hoy en día.

Y más aún, los libros que tratan de la vida y la historia de los caballeros describen con todo detalle la familia, el tiempo, el lugar y la acción de este o de aquel caballero día a día. Basado en estos datos, Don Quijote puede describir el Amadís de Gaula con todos sus rasgos, características y acciones, de tal manera que podría decirse que él lo había visto con sus propios ojos. A esto lo llama él una "verdad cierta" acerca de su existencia (p. 359). Además, ¿puede ser posible que libros impresos con licencia real mientan? Y ¿cómo puede dudarse de que los gigantes tengan existencia real? En la Isla de Sicilia se han descubierto tibias y omóplatos de tal tamaño, que demuestra que sus poseedores eran gigantes tan altos como una torre. También las Sagradas Escrituras, que no pueden alejarse de la verdad en lo más mínimo, hablan de gigantes como Goliat (p. 359). Si examinamos por qué nosotros, dentro de la realidad de nuestra actitud natural, creemos en acontecimientos históricos, podemos echar mano de argumentos similares a los de Don Quijote: documentos monumentos ininterrumpida tradición y relatos fidedignos. $Y$ podría haber aún discusiones bien fundadas entre los historiadores del mundo de Don Quijote, tales como la discusión que él tuvo con el loco Cardenio sobre si el maestro Elisabat era o no el amante de la Reina Madásima (p. 146).

La caballería andante es antes que nada un modo de vida; cumple una misión celestial. Los caballeros andantes son "ministros de Dios en la tierra, y brazos por quien se ejecuta en ella su justicia" (p. 70). En esta edad de hierro su profesión es la de recorrer el mundo, enderezando entuertos y remediando injusticias (p. 116). Pero la caballería no es sólo un modo de vida, es una ciencia; aún más, es la reina de todas lás ciencias, que comprende todas o casi todas las ciencias del mundo. Quien profesa la caballería andante debe ser un jurista y dêbe saber tâs teyes sobre la persona y la propiedad; debe ser teólogo, para poder dar las razones de las reglas cristianas que profesa; médico, y especialmente conocer de hierbas, para poder preparar una redoma del bálsamo de Fierabrás, del cual bastan unas gotas para curar a un caballero que ha sido partido por en medio, siempre y cuando las partes sean unidas con exactitud antes de que "la sangre se yele" (p. 57); astrónomo, para saber por las estrellas cuántas horas de la noche han pasado y en qué parte del mundo se halla uno; debe saber herrar un caballo, aderezar la silla y el freno y nadar. $Y$ sobre todo tiene que ser mantenedor de la verdad, aunque el defenderla le cueste la vida (p. 437).

3 Todas las citas se refieren a la edición de la Colección Austral, Espasa-Calpe Argentina, Buenos Aires, 1941. 
Este mundo de la caballería andante tiene su propio sistema económico y jurídico. Los caballeros andantes están exentos de toda jurisdicción; su ley es su espada, su fuero es su valor, su norma su propia voluntad ( $p .309$ ). ¿Dónde se ha oído de un caballero andante que haya sido llevado ante un juez por muchos homicidios que hubiese cometido? (p. 56). ¿Qué caballero andante pagó nunca impuestos o derechos aduanales o derechos de pontazgo? ¿Cuándo un caballero pagó a un sastre por el traje o las ropas que le hizo? ¿Qué castellano que alojó a un caballero en su castillo le obligó a pagar por ello? (p. 309). Y, naturalmente, los caballeros andantes nunca pagaron sueldo a sus escuderos. Los hicieron gobernadores de alguna isla o algún reino conquistado (p. 383).

Este sub-universo está caracterizado por peculiares modificaciones de las categorías fundamentales del pensamiento, es decir, las del espacio, tiempo y causalidad. El reino de Micomicona en Etiopía (p. 188) y el Imperio de Trapisonda (p. 21) son conceptos geográficos bien determinados; la segunda región del aire donde se engendran el granizo y la nieve, y la tercera del fuego donde se engendran los relámpagos y los truenos (p. 550), están establecidas por la física celestial. $\mathrm{Y}$ todos estos lugares pueden ser traídos al alcance de uno. El sabio, nigromante, o mago, que cuida del caballero -y naturalmente cada caballero, para serlo de verdad, tiene esa clase de protector (p. 202)- lo toma dormido en su cama y al día siguiente lo deja miles de leguas más allá del lugar en que estaba; o le manda un carruaje de fuego, o un Hipogrifo, o un Clavileño, el caballo de madera, o una nave encantada. Si no fuera por esto, no sería posible que un caballero, luchando en las montañas de Armenia contra algún dragón, fuera salvado al final por su amigo (o protector), quien se encontraba un momento antes en Inglaterra (p. 202). Don Quijote pasa tres días en la cueva de Montesinos, aunque quienes lo aguardan en la entrada de la cueva digan que sólo estuvo dentro poco más de una hora (p. 466) -un problema semejante al que ha analizado Bergson en nuestros días al tratar del concepto de tiempo en la teoría de la relatividad de Einstein-. Todo esto es debido a la obra de los encantadores, tanto de los amigos como de los enemigos, que desempeñan en el sub-universo de Don Quijote el papel de causalidad y motivación. Su actividad es la categoría fundamental de la interpretación del mundo de Don Quijote. Su función es la de trasladar el orden del reino de la fantasía al reino de la experiencia del sentido común; por ejemplo, transformar a los gigantes atacados por Don Quijote en molinos de viento. Los encantadores pueden, por lo tanto, transformar todas las cosas y cambiar su forma. Pero, hablando estrictamente, lo que ellos transforman es el modo de interpretación que es válido en otro sub-universo. Los dos modos de interpretación se refieren a la misma cosa; por ejemplo, la pieza de metal amarillo, de forma especial, yelmo milagroso de Mambrino en los térmi- 
nos del sub-universo particular de Don Quijote, y una ordinaria bacía de barbero en los términos de la realidad cotidiana de Sancho Panza.

Así, pues, la función de los encantadores es precisamente la de garantizar la coexistencia y compatibilidad de varios sub-universos de significaciones referidas a las mismas cosas y de asegurar la persistencia de la dimensión de realidad otorgada a cualquiera de dichos sub-universos. Nada permanece inexplicado, paradójico o contradictorio, tan pronto como las actividades de los encantadores se reconocen como elemento constitutivo del mundo. Pero, para Don Quijote, la existencia de encantadores es mucho más que una mera hipótesis. Es un hecho histórico probado por las fuentes de todos los libros sagrados que tratan de asuntos de caballería. Por supuesto, este hecho no puede ser comprobado por los medios ordinarios de la percepción sensible, porque los magos nunca permiten que se les vea (p. 92) y es claro que el axioma de encantamiento, que efectúa la reconciliación entre el sub-universo de la fantasía y la primordial realidad posible, no puede ser sometido a prueba, pues ésta se fundaría precisamente_en_uno de esos sub-universos.

Nuestro tiempo, con su ilustración, no está preparado para aceptar la intervención de encantadores invisibles como principio de explicacion de los hechos en la estructura causal del mundo. Nosotros, en efecto, reconocemos la existencia de virus invisibles, o de neutrones, o de un $I d$, en el sentido que esta palabra tiene en el psicoanálisis, como fuentes causales de fenómenos observados. Pero ¡quién se atrevería a comparar estos hallazgos de nuestros científicos con las actividades de los encantadores del loco Don Quijote! Sin embargo, desde el punto de vista de Don Quijote, la actividad de-los encantadores invisibles tiene una gran ventaja sobre los principios explicativos de la ciencia moderna que se acaba de mencionar. Los encantadores tienen sus motivos para actuar como lo hacen y estos motivos son comprensibles para nosotros,-los seres. humanos. Algunos de ellos tienen ojeriza al caballero porque saben bien, gracias a su arte y encantamiento, que a la larga Don Quijote vencerá a uno de sus favoritos caballeros en combate y que ellos no serán capaces de impedir que se realice lo que el Cielo ha decretado (p. 44). Pero los encantadores propicios también interfieren: el sabio que está de parte de Don Quijote muestra una rara clarividencia al hacer aparecer ante todos el Yelmo de Mambrino, objeto de tan inmenso valor, como una bacía de barbero; protegiendo así a su dueño de ser perseguido por aquellos que vieran la verdadera realidad (p. 151). Y también sucede, por ejemplo en el pasaje de la aventura milagrosa con el barco encantado, que dos poderosos encantadores choquen entre sí, cada uno tratando de frustrar el designio del otro (p. 497). Aquí tenemos todos los elementos de la teología griega en la época de Homero. La envidia de los dioses, la intervención en favor de sus protegidos, la lucha por el poder y su sumisión inevitable al hado. Ciertamente, si introducimos a los encantadores dentro de la cadena causal, no podemos resolver la duda cartesiana de si el mundo 
está gobernado por un genio del mal e por Dios. Pero estamos seguros de que lo que puede pasar, pasa razonablemente, a saber: dentro de las motivaciones de los encantadores. Podemos estar tentados de hablar de una dialéctica no hegeliana, de una manera parecida a cuando hablamos de una geometría no euclidiana.

Tales son los rasgos principales del sub-universo hermético de Don Quijote al cual él ha otorgado una dimensión de realidad; de la base desde la cual él interpreta todas las demás provincias de la realidad. Pero este mundo suyo entra en contacto con el mundo de sus prójimos, y ambos, Don Quijote y los otros, tienen que atenerse a los conflictos que se suscitan entre los esquemas disparejos de interpretación que rigen para cada uno de los dos mundos. En la descripción de varias de las aventuras que Don Quijote encuentra en sus tres salidas, Cervantes presenta de manera sistemática las soluciones típicas para este probtema; y sería una tarea muy tentadora la de analizarlas paso a paso. Este propósito no puede llevarse a cabo dentro del marco de este trabajo. Tenemos que limitarnos a hacer sólo una consideración general y a analizar sólo algunas de las aventuras de Don Quijote.

El mundo social con que Don Quijote entra en contacto en cada una de sus tres salidas toma una actitud radicalmente diferente frente a su fantástico mundo particular, que es para él eminentemente un mundo lleno de sentido, pero que resulta para el prójimo un mundo de locura. En su primera y breve salida, Don Quijote va solo. Va meramente entretenido en un diálogo íntimo con un mago desconocido, quienquiera que éste sea, que va a transmitir la crónica de sus hazañas a las generaciones futuras. Mas, por otra parte, Don Quijote sigue como amo imperturbable en su sub-universo; no se considera refutado por el comportamiento de sus semejantes, quienes, como afirma_Cervantes, deciden "seguirle el humor" (p. 27).

Para Don Quijote existen realmente la fortaleza con torres y capiteles de plata luciente, la trompeta de un enano anunciando al caballero que llega, doncellas bellísimas tomando el fresco a la puerta del castillo, y el alcaide de este castillo. Solamente para el observador existen una venta, un porquero sonando su cuerno, dos mujeres de virtud incierta y un ventero. Nada ni nadie, sin embargo - para volver a la cita de William James hecha al principio de este trabajo-, comienza un altercado diciendo algo inadmisible que pudiese contradecir la experiencia de Don Quijote, que éste tiene por verdadera. El ventero lo recibe a él como corresponde a un caballero, le permite velar las armas y lleva a cabo la ceremonia de armarlo caballero; nada hacen tampoco los mercaderes que están reacios a reconocer sin prueba que Dulcinea sea la más hermosa de las doncellas, ni los arrieros se comportan de una manera incompatible con el patrón de interpretación que rige en el mundo de la caballería. Así, pues, las acciones de Don Quijote pueden ser ejecutadas dentro de la realidad primordial de la vida cotidiana a pesar de sus motivos fantásticos, y no 
hay necesidad de llamar a los encantadores para que vengan a conciliar lose esquemas dispares de interpretación.

La actividad de los encantadores aparece por primera vez durante el episodio entre la primera y la segunda salidas, cuando el cura y el barbero tratan de curar a Don Quijote quemando sus libros y haciendo un escrutinio de su biblioteca. Este hecho es explicado como obra del archienemigo de Don Quijote, el mago Frestón; y el caballero entiende esto perfectamente bien, y lo toma como un hecho verdadero. Desde entonces Don Quijote usa el hecho del encantamiento para mantener la dimensión de realidad de su sub-universo particular de la caballería andante cuando este mundo choca con la realidad primordial de aquellos de sus semejantes que se ponen en contacto o en conflicto con él. En esta segunda salida, Don Quijote ya no va solo. Tiene que establecer un "sub-universo de comunicación" con el compañero con quien está en relación directa dentro del mundo del sentido común. Esto se refiere sobre todo a Sancho Panza, su escudero, el representante del pensamiento cotidiano, que tiene siempre un tesoro de proverbios a sus órdenes para poderlo explicar todo en términos del conocimiento que se tiene por obvio. Pero si las cosas y los hechos que ambos experimentan son interpretados mediante esquemas diferentes de interpretación, ¿ison todavía experiencias comunes de los mismos objetos? Nuestra relación con el mundo social se basa en el supuesto de que, a pesar de todas las variaciones individuales, el prójimo experimenta os mismos objetos esencialmente de la misma manera que nosotros, y viceversa; $\mathrm{y}$ también que sus esquemas de interpretación y los nuestros ofrecen la misma estructura típica de conexiones. Si esta creencia en la identidad esencial de Ta experiencia intersubjetiva del mundo se viene abajo, entonces se destruye la posibilidad misma de establecer comunicación con el prójimo. En tan crítica situación llegamos a convencernos de que cada uno de nosotros vive dentro de la concha impenetrable de su propia prisión solipsística; los demás resultan solamente meras ilusiones para nosotros, para los demás, y nosotros para nosotros mismos. Hay dos posibilidades: o bien mis experiencias del mundo objetivo resultan meras ilusiones (y en la terminología de Don Quijote esto quiere decir que el encantador ha transformado el mundo objetivo), o yo he cambiado mi identidad (lo cual quiere decir que yo estoy encantado). Por otra parte, es precisamente la supuesta actividad de los encantadores quienes cambian y alteran todas nuestras hazañas y las transforman según su capricho, lo que conduce al efecto de que lo que a Don Quijote le: parece el Yelmo de Mambrino sea para Sancho Panza una bacía de barbero, y para otro algo diferente (p. 50). Esto no es del gusto de Sancho Panza. Para él, el empírico neopositivista, los dolores de sus hombros cańsados por el manteo de que fué objeto en la posada confirman la realidad de sus atormentadores, el pósadero y el arriero; y se niega a aceptar la explicación de Don Quijote de que ellos eran fantasmas de un castillo encantado. Cuando 
se comienza a reconocer a gentes que tienen nombres, dice Sancho, no existe ningún encantamiento. Pero, lentamente, Sancho va aceptando el esquema de interpretación de Don Quijote. El encantamiento resulta al fin posible para Sancho; y, así, al término de la segunda parte, después de la derrota de Don Quijote por el Caballero de la Blanca Luna, se convierte en un hecho. "Parecíale que todo aquel suceso pasaba en sueños, y que toda aquella máquina era cosa de encantamiento" (p. 671).

Con gran habilidad, Cervantes describe esta transición y los medios por los cuales un mismo sub-universo de comunicación se establece entre el caballero y el escudero. Ambos tienen buenos argumentos para explicar sus discrepancias. Don Quijote reconoce que Sancho no es un caballero y, por lo tanto, está sujeto a otras leyes (p. 94); quizá su miedo le impide ver y escuchar lo que en verdad es (p. 100); si Sancho siguiera furtivamente los dos rebaños de ovejas por un momento, descubriría que fueron transformados en dos ejércitos tal y como lo describió Don Quijote (pp. 101-102). Por otra parte, Sancho Panza se inclina a creer que las desgracias del caballero se deben al hecho de que Don Quijote quebrantó un juramento solemne (p. 104); o tal vez a que tiene poderes sobre gigantes reales, pero ningún poder sobre fantasmas (p. 187). Y habiendo descubierto que él tiene que aceptar el encantamiento como un esquema de interpretación, para poder establecer un universo de comunicación con Don Quijote, Sancho aprende a expresarse como un discípulo de los filósofos escépticos. Sancho corrige varias veces su juicio original sobre lo que Don Quijote declara que es el Yelmo de Mambrino, y que para él es sólo una bacía de barbero, que tiene el valor de un real, si es que tiene algún valor: "que no semeja sino una bacía de barbero, pintiparada" (p. 119). Y después (p. 304) habla incluso de un baciyelmo. Hacia el final de la primera parte (p. 304) el relato de esta aventura se usa para desarrollar, como en un stretto de complicada fuga, el tema principal de la realidad intersubjetiva en nuevas elaboraciones. En la posada - para Don Quijote, un castillo encantado- se han reunido todos los actores principales del relato. El barbero, antiguo propietario del baciyelmo, que Don Quijote ha adquirido en debido combate, aparece y reclama su propiedad, y también la albarda que Sancho le había quitado a su mula en aquella ocasión. La compañía en la posada decide seguir adelante con la broma y confirma, para desesperación del dueño despojado, que el objeto en cuestión es, como Don Quijote mantiene, un yelmo y no una bacía de barbero. La opinión de un perito, proporcionada por el maestro Nicolás, el barbero amigo de Don Quijote, corrobora este descubrimiento. El antiguo propietario no puede entender cómo tantos caballeros honorables pueden decir que el objeto en disputa no es una bacía sino un jelmo. Pero si esto es así, él arguye, entonces la albarda de su mula debe ser un arnés de caballo, ya que Don Quijote mantiene que encontró al barbero cuando éste montaba un caballo rucio. En términos de lógica formal, este argumento es 
perfectamente correcto. Don Quijote se niega a intervenir en el asunto de la albarda, porque éste no se refiere a cuestiones de caballería andante y él, siendo caballero, pudiera estar sujeto a sortilegios en aquel castillo encantado. Don Quijote reconoce que esa cosa le parece a él una albarda; pero deja la decisión a los demás, porque su entendimiento estará libre y así podrán juzgar los acontecimientos de aquel castillo tal como son, y no como a él se le presentan. Quienes están en el enredo afirman, por medio de un voto secreto, que el objeto no es la albarda de una mula sino el arnés de un caballo. El antiguo propietario, bajo cuya mirada los objetos se han convertido en yelmo y en arnés, está más que perplejo; pero, como buen demócrata, acepta el voto de la mayoría y dice "Allá van leyes" (donde quieren reyes) (p. 306). Uno de los presentes, empero, asumiendo el papel de observador científico, no está satisfecho.

Si eso no es una broma tramada, él no llega a entender cómo unos hombres inteligentes pueden insistir en que los objetos en cuestión no sean una bacía y una albarda. Este juicio se presenta como contrario a la verdad obvia y al buen sentido, y el mundo entero no lo convencerá a él de lo contrario. Como un buen método para decidir tal disputa, se inicia una batalla general entre las dos partes. "Finalmente -comenta Cervantes- el rumor se apaciguó por entonces, la albarda se quedó por jaez hasta el día del Juicio, y la bacía por yelmo, y la venta por castillo" (p. 307). El abismo entre los dos sub-universos no se puede zanjar ni por medio de la lógica formal, ni por medio del voto de la mayoría, ni por medio de la victoria militar.

La segunda parte de la novela, escrita diez años después, traspone la dialéctica de la intersubjetividad a una nueva dimensión. En sus dos primeras salidas Don Quijote tropezó con varias personas y se enfrentó con ellas en relación directa, sin que ninguna de las partes tuviera un conocimiento previo de la otra. Pero antes de que Don Quijote saliera por tercera vez, la historia de sus aventuras anteriores había sido descrita en un libro leído por la mayor parte de las personas que él habría de encontrar. Ese público anónimo de lectores se había formado un tipo ideal de la personalidad de Don Quijote y de sus maneras de actuar y reaccionar; esos lectores esperan de él determinadas formas de comportamiento, entre ellas, las expectativas que Don Quijote tendrá respecto de las reacciones de ellos, y se preparan a orientar su propio comportamiento hacia el caballero de manera tal, que pueda ser interpretado por él como una respuesta adecuada a sus propias acciones. Para halagarlo, para establecer con él un adecuado universo de comunicación, construyen, dentro de la realidad de su mundo cotidiano, un mundo de juego, de broma, de ficción y de simulación, y esperan que Don Quijote lo tome como la realidad, en los términos de su particular sub-universo. Pero, dado que nunca otorgaron una dimensión de realidad a su mundo de ficción, no pueden tener éxito en establecer un universo de comunicación con Don Quijote, y, por consiguiente, 
no pueden establecer una verdadera relación social con él. Esto lleva, como veremos, a la tragedia personal y a la caída del caballero.

La tragedia personal de Don Quijote se debe, ante todo, al debilitamiento de su fe en la realidad de Dulcinea. Cuando Sancho se entera de que la dama del caballero, Dulcinea del Toboso, no es sino la hija de un labrador, llamada Aldonza Lorenzo, duda de todo lo que el enamorado caballero ha dicho de ella. "¿Piensas tú que las Amarilis, las Filis, las Silvias, las Dianas, las Galateas, las Fílidas, y otras tales de que los libros, los romances, las tiendas de los barberos, los teatros de las comedias, están llenos, fueron verdaderamente damas de carne y hueso, y de aquellos que las celebran y celebraron? ( $\mathrm{p}$. 155). No, por cierto, sino que las más se las fingen, por dar sujeto a sus versos, ...y así, bástame a mí pensar y creer que la buena de Aldonza Lorenzo es hermosa y honesta; $y$ en lo del linaje, importa poco; que no han de ir a hacer la información dél para darle algún hábito, y yo me hago cuenta de que es la más alta princesa del mundo." Y aquí Don Quijote hace un juicio que es el meollo de nuestro problema y supera con su audacia lógica todas las paradojas de la teoría de las clases de Russell: " $Y$ para concluir con todo, yo imagino que todo lo que digo es así, sin que sobre ni falte nada...” (p. 155). Este es el axioma básico que identifica la verdad con la existencia en el sub-universo al cual se haya otorgado una dimensión de realidad.

En la segunda parte de la novela, la Duquesa recibe a Don Quijote en el mundo de simulación que ella ha urdido, cuidadosamente, para él. Y refiriéndose al mencionado juicio sobre el caballero que ella leyó en la primera parte ya publicada, como también al hecho de que Don Quijote nunca se encontró con Dulcinea, expresa duda sobre la existencia real de dicha dama. "Dios sabe si hay Dulcinea, o no, en el mundo, o si es fantástica, o no es fantástica; $y$ éstas no son de las cosas cuya averiguación se ha de llevar hasta el cabo. $\mathrm{Ni}$ yo engendré ni parí a mi señora, puesto que la contemplo como conviene que sea una dama que contenga en sí las partes que puedan hacerla famosa en todas las del mundo" (pp. 511-512). Solamente los mercaderes de Toledo que van a comprar seda a Murcia quieren que el caballero les enseñe a Dulcinea, o cuando menos un retrato, antes de mostrarse dispuestos a aceptar que sea una muy hermosa doncella (p. 34). Sólo Sancho se atreve a decirle a Don Quijote, durante la tercera salida, cuando buscan en vano el palacio de Dulcinea en el Toboso, que él tampoco vió nunca a la incomparable dama y que su relato de haberla visto y la respuesta que le trajo al caballero fueron cosas de su invención. Pero esto no es bastante. Tres labradoras en sus borricos se acercan por el camino y Sancho se las describe a Don Quijote como la princesa Dulcinea en toda su gloria, acompañada de sus damas, cabalgando hacaneas blancas como la nieve. Pero Don Quijote, para desesperación suya, puede ver

4 La cual se encuentra también en la novela de Cervantes, como ya lo descubrió Hermann Weyl. 
solamente labradoras montadas sobre borricos -al menos eso es lo que le parece a él (p. 396) - y se inclina a dudar de su propia experiencia inmediata. Con toda seguridad, los encantadores han puesto nubes y cataratas en sus ojos y para éstos solamente, y no para otros, se ha transformado Dulcinea en una pobre labradora. Y todavía hay una posibilidad más terrible. Quizá el encantador, al mismo tiempo, le dió a Don Quijote la apariencia de algún espectro para hacerlo abominable a los ojos de Dulcinea (p. 397). Este es el mismo problema que presenta Kafka en su novela Metamorfosis, en la cual un hombre se encuentra una mañana transformado en un bicho gigantesco. Don Quijote comienza a dudar de su propia identidad. La situación se vuelve todavía más complicada por el hecho de que más tarde Don Quijote, en la visión que tiene en la cueva de Montesinos, ve a Dulcinea transformada en una campesina, y llega entonces a la conclusión de que ella debe estar encantada, transformada, no sólo para él, sino también para Sancho y para todos los demás. Sin embargo, Don Quijote tiene dudas, y las sigue teniendo, sobre si lo que vió en la cueva de Montesinos fué algo real, un sueño, o pura imaginación suya. Pregunta al mono adivino de Maese Pedro (p. 478), y más tarde a la cabeza encantada (p. 659), si el relato que él dió de sus experiencias en la cueva era verdad o sueño, imaginación o realidad, y recibe dos veces la respuesta de que era una mezcla de ambas cosas. Incluso dentro del sub-universo particular de Don Quijote hay la posibilidad del ensueño y de la imaginación, un mundo de fantasía dentro del mundo de la fantasía; aun en ese sub-universo las fronteras de la realidad son evanescentes; incluso en él hay enclaves que constituyen reflejos de otros sub-universos.

Para Sancho, que sabe que todo el relato de sus dos encuentros con Dulcinea es nada más que invención suya, la situación aparece completamente clara, y la narración de Don Quijote de lo que vió en la cueva de Montesinos lo convenció finalmente, sin ninguna duda, de que su amo estaba fuera de su juicio y loco en todos los sentidos (p. 467). Pero su acertada convicción se tambalea cuando, más tarde ( $p .516$ ), confiesa a la Duquesa que él hizo que Don Quijote creyera en la verdad de sus encuentros con Dulcinea, y que el encantamiento de dicha dama es tan verdad como que la luna es un queso verde. La Duquesa contesta que, en su opinión, el truco de Sancho fué una invención de los encantadores, y que la labradora es real y verdaderamente Dulcinea, y que fué él, el buen Sancho, quien resultó engañado, aunque pensara que él había sido el engañador. Con esto, la Duquesa toma el punto de vista hegeliano de "los artilugios de la Razón", que hacen que el hombre, involuntaria e inconscientemente, sea un instrumento de los superiores fines de ella, Sancho tiene que aceptar esta posibilidad, y también que, si la Duquesa tiene razón, tenga él que creer lo que Don Quijote pretende haber visto en la cueva. Pero, manifiesta Sancho, debió haber sido al revés de lo que la Duquesa dice. No se puede suponer que Sancho pudiera inventar $\tan$ astuto truco con su 
pobre ingenio, aguijoneado por el problema del momento; ni su amo puede estar tan loco como para dejarse persuadir por las débiles dotes de algo tan considerablemente más allá de toda probabilidad. La verdad debe ser que/ lo que él vió era una labradora, la tomó por labradora, y como labradora la juzgó. Pero, si era Dulcinea, esto no puede atribuírsele a él, sino tan sólo a la obra de un encantador muy activo y extremadamente listo (p. 519). La aceptación, por parte de Sancho, de la posibilidad de que su labradora empírica, a quien él transformó en una Dulcinea ficticia, era quizás en efecto la Dulcinea nouménica, completa la dialéctica de la experiencia intersubjetiva de la realidad.

Se mencionó antes que el mundo de la fantasía no es un reino unificado; que hay fantasías dentro de las fantasías, sub-universos dentro de los subuniversos, los cuales pueden chocar uno con otro, y ambos con la realidad de la vida cotidiana. Un ejemplo de tal situación puede encontrarse en uno de los más profundos capítulos de la obra de Cervantes, en el cual Don Quijote asiste a la función de los títeres de Maese Pedro para ver "La Liberación de Melisandra". Por sus libros de caballerías, Don Quijote conoce todos los detalles del relato de cómo Don Gaiferos libera a la señora Melisandra de la esclavitud de los moros en que se encontraba, que es para él un hecho histórico. Al comienzo de la función, Don Quijote critica ciertos detalles de presentación como contrarios a los hechos; por ejemplo, que el Rey moro da la señal de alarma para la persecución de los enemigos batiendo las campanas de las torres de todas las mezquitas, cuando en realidad los moros usaban para tal propósito atabales y dulzainas. Pero pronto la representación teatral se apodera de Don Quijote y crea en él miedo y compasión, al buen modo aristotélico. Las cosas que sabía por sus libros, que eran hechos históricos, ocurren ahora, representadas por los títeres de Maese Pedro, ante sus ojos, vívidamente en el presente. Mientras dura la función, el curso de los acontecimientos permanece todavía incierto, y puede ser influído por la interferencia de Don Quijote; éste, viendo la partida de moros en persecución de los fugitivos, piensa que su deber es ayudar a un rey tan famoso y a una dama tan hermosa. Desenvaina su espada y comienza a dar de cuchilladas con terrible furia sobre los títeres que hacían de moros, sin atender la exortación del desesperado Maese Pedro, que le advertía que aquéllos no eran moros reales, sino figurillas de pasta. Después, cuando Maese Pedro pide el pago por el daño causado a su propiedad, Don Quijote le asegura (p. 483) que todo lo que había pasado le había parecido a él un hecho verdadero. Melisandra era Melisandra, Gaiferos era Gaiferos, Carlomagno era Carlomagno. Por esto se le excitó la cólera, y consciente de su misión de caballero andante, tuvo que dar ayuda y protección a los perseguidos.

Don Quijote toca aquí el profundo problema, todavía no resuelto, de la realidad de la obra artística, especialmente del teatro. También nosotros, San- 
chos del mundo del sentido común, al sentarnos entre el público estamos dispuestos a substituir la dimensión de realidad del mundo circundante đe nuestra vida cotidiana por el mundo del escenario, tan pronto como el telón se levanta. Tambien nosotros, mientras el drama se desarrolla, vivimos en un reino de realidad diferente al de los entreactos. También para nosotros Lear es Lear, Regan es Kegan, Kent es Kent. Pero esta realidad de los acontecimientos en el escenario es de una clase enteramente diferente de la de nuestra vida cotidiana.

Esta última es el único sub-universo dentro del cual podemos manejarnos con nuestros propios actos, el único sub-universo que podemos transformar con nuestra acción y dentro del cual podemos establecer comunicacion con nuestros próimos. Este carácter fun damentâ de la realidad de nuestra vida cotidiana (¿o se trata tan sólo de que axiomáticamente le otorgamos la dimensión de realidad?) esprecisamente la razón por la cual este sub-universo lo experimentamos como realidad primordial de las circunstancias y del contorno con que tenemos que habérnostas:

Nosotros, los espectadores, carecemos de poder con respecto a la realidad de la obra de arte o del teatro; en tanto que espectadores, tenemos que sufrirla o gozarla, pero no estamos en posición de intervenir en ella, de cambiarla con nuestras acciones. Aquí tenemos quizá una de las raíces de la estructura tenomenológica de la experiencia estética. Pero el seguir el desarrollo de esta idea nos llevaría muy lejos.

A toda costa, Don Quijote toma como base un sub-universo que no es ni mucho menos la realidad primordial de la vida cotidiana. Por esto no puede darse cuenta de que el mundo del teatro está separado de la fantasía propia de su sub-universo privado. Melisandra y su liberación son también partes del contorno en su mundo de la caballería. Estrictamente hablando, encontramos en su aventura con los títeres el choque entre tres reinos de realidad: el mundo fantástico de la caballería, en el cual un caballero tiene que intervenir para ayudar a una hermosa dama; el del teatro, en el cual todo está representado de modo ficticio por actores de carne y hueso o por títeres, y el cual no admite intervención alguna del público; y tercero, la triste realidad de la vida cotidiana, en la cual se pueden aplastar figuras de pasta, y en la cual el dueño dèl espectáculo presenta una cuenta por el daño que ha causado la irrupción de nuestros ensueños en el mundo de la realidad.

Otra aventura, la del barco encantado, describe el choque entre otros tres reinos de realidad: el mundo de la caballería, el del sentido común y.el de la ciencia. Don Quijote y Sancho, cabalgando a lo largo del río Ebro, encuentran un pequeño barco sin remos, que estaba atado en la orilla del tronco de un árbol. Don Quijote cree que ese barco "sin poder ser otra cosa en contrario" (p. 656) lo invita a embarcarse y navegar dos o tres míl leguas en un abrir y cerrar de ojos, para socorrer a alguna persona noble en apuros. Atan 
a un árbol a Rocinante y al rucio de Sancho, se embarcan y levan anclas. Mientras que Sancho está lleno de miedo y desesperación, porque oye a su rucio rebuznar ansiosamente, Don Quijote cree que han navegado ya más de setecientas u ochocientas leguas, o tal vez más, y que atravesarán muy pronto, si no la han atravesado ya, la línea equinoccial, la cual, de acuerdo con los cómputos de Ptolomeo, el cosmógrafo más famoso de cuantos ha habido, divide y corta los polos opuestos en igual distancia. Para verificar esta creencia, Don Quijote se sirve de los métodos exactos de las ciencias naturales. El primer método sería tomar exactamente, con ayuda de un astrolabio, la altura del Polo, pero Don Quijote no dispone de tal instrumento. El segundo método es hacer un experimento que se basa en una ley empírica, la cual parece que se ha comprobado $y$, por lo tanto, como diríamos en lenguaje moderno, ha sido aceptada en los anales de la ciencia geográfica. La ley, descubierta y probada por los españoles y cuantos embarcan en Cádiz para ir a las Indias Orientales, establece que al pasar la línea equinoccial "a todos los que van en el navío se les mueren los piojos sin que les quede ninguno" (p. 495). Sancho tiene que pasar por esta experiencia científica. Si pasa su mano sobre su muslo y coge algo vivo, sabrán que aún no atravesaron la línea; y si nada encuentra, sabrán que ya la atravesaron. Sin embargo, empleando su sentido común, Sancho protesta vigorosamente. No hay necesidad de hacer este experimento, dice, porque él puede ver con sus propios ojos que no se han apartado dos varas de donde están Rocinante y el rucio. Ante esta objeción tan falta de ciencia, Don Quijote toma la posición del científico rigurosamente empírico, que, atrincherado en su sub-universo de realidad científica, pide la verificación de cualquier juicio empírico. "Haz, Sancho, la averiguación que te he dicho, y no te cures de otra; que tú no sabes qué cosa sean coluros, líneas, paralelos, zodíacos, eclíticas, polos, solsticios, equinocios, planetas... de que se compone la esfera celeste y terrestre; que si todas estas cosas supieras, o parte dellas, vieras claramente qué de paralelos hemos cortado, qué de signos visto, y qué de imágenes hemos dejado atrás, y vamos dejando ahora. Y tórnote a decir que te tientes y pesques, que yo para mí tengo que estás más limpio que un pliego de papel liso y blanco" (p. 493).

Sancho obedece, levanta la cabeza, mira a su amo y dice: "O la experiencia es falsa, o no hemos llegado adonde vuesa merced dice, ni con muchas leguas" (p. 495).

Claramente, el sub-universo de la interpretación científica del mundo choca aquí con el del sentido común. Pero no necesitamos de la actividad de encantadores para reconciliarlos. Existe todavía la posibilidad señalada por el gran metodologista Sancho: la prueba puede ser falsa. Si la teoría de que todos los piojos mueren cuando el barco cruza la línea equinoccial es una ley empírica, y si resulta que la línea se ha cruzado indudablemente, a pesar de que se han encontrado piojos vivos, entonces la ley queda invalidada por este 
solo hecho contradictorio, y tiene, por lo tanto, que ser eliminada de los anales de la ciencia y reemplazada por otra que esté mejor fundada. Esto es así, porque el sub-universo cerrado de la realidad científica, aunque necesariamente diferente del sub-universo del sentido común de la vida cotidiana, está atado también necesariamente al proceso de verificación empírica dentro del mundo del sentido común en el cual vivimos y al que tomamos como nuestra realidad primordial.

Por otra parte, el que nosotros veamos con nuestros propios ojos a Rocinante y al rucio de Sancho no es ninguna objeción al requisito científico, necesario para averiguar nuestra ubicación dentro del universo, en relación con las realidades científicas de coluros, líneas, eclípticas, etc. Y si sucede que el ver nosotros a Rocinante fué solamente una ilusión, una mera apariencia o fantasma, entonces la explicación científica, para que sea válida y real, en relación con el sub-universo de la ciencia, tiene que mantener abierta, si no es que ha de explicarla, la posibilidad de tal ilusión dentro de la realidad primordial del sentido común. Pero es más interesante aún el darse cuenta de que también el sub-universo ficticio de Don Quijote conoce hechos reales y creencias susceptibles de un análisis controlado y de una verificación empírica; y de que tal universo puede resultar compatible o incompatible con el sub-universo de la ciencia, tanto como lo puede resultar nuestro mundo del sentido común.

Es decir, desde el punto de vista del mundo del sentido común, los "hechos reales y efectivos" en el mundo de Don Quijote son meros fantasmas. Pero también la ubicación en el espacio ficticio de Don Quijote, en el cual podemos viajar muchos miles de leguas en un abrir y cerrar de ojos, es todavía una ubicación dentro del universo entero, el mismo universo que puede ser descrito en términos del sistema científico de coluros, líneas, eclípticas, etc. E] análisis más penetrante del problema de la ilusión y la percepción y de la intersubjetividad, como etementos constitutivos de la realidad, se halla en el capítulo que describe el viaje de Don Quijote y Sancho en Clavileño, el caballo de madera. Desgraciadamente, no podemos hacer aquí una descripción detallada de los hechos ocurridos en la corte del Duque y la Duquesa, quienes al establecer un mundo de ficción preparan cuidadosamente esta aventura extraordinaria, la cual en mi opinión constituye la cumbre de la leyenda de Don Quijote.

Le dicen a Don Quijote que un caballo de madera, Clavileño, ha sido enviado por un mago para llevarlo a él y a su escudero por el aire hasta un reino distante, donde una afligida dama necesita socorro. Montan a Don Quijote y a Sancho en la parte de atrás del caballo de madera y les vendan los ojos. De acuerdo con lo que le han dicho, el caballero mueve la clavija de madera que pondrá en movimiento al caballo, y el viaje comienza. De la manera más refinada, preparan artificios para darle giros de verdad a la ilusión del vuelo de nuestros viajeros, quienes, por supuesto, no abandonan la tierra. La gente 
grita: “¡Ya, ya vais por esos aires, rompiéndolos con más velocidad que una saeta!" (p. 549).

Sancho, pensando aún en términos de sentido común, pregunta: "Señor, ¿cómo dicen éstos que vamos tan altos, si alcanzan acá sus voces, y no parece sino que están aquí hablando, junto a nosotros?” (p. 549).

Acertadamente Don Quijote señala que el esquema de interpretación en términos de la realidad del sentido común ya no se puede aplicar a situaciones que, trascendiendo esta realidad, invalidan los fundamentos axiomáticos de todas las explicaciones que rigen dentro del sub-universo que ellos acaban de dejar. Cegados, o con los ojos vendados, como estamos cuando nos sumergimos en el reino de lo trascendental, no podemos verificar el testimonio del prójimo por medio de nuestras percepciones sensoriales. Es el mismo problema que, casi al mismo tiempo que Cervantes, trató Shakespeare en la grandiosa escena de El Rey Lear (IV-6), cuando Edgar le hace creer al cegado Gloucester que saltó del risco de Dover para matarse, pero sobrevivió.

Don Quijote, en su caballo inmóvil, siente una brisa que le azota, causada por fuelles operados por los sirvientes del Duque; y siente calor gracias a unas estopas que pendientes de una caña le calentaban el rostro. Aplicando su conocimiento científico para explicar sus sensaciones en términos del reino de la fantasía, Don Quijote hace saber a Sancho sus conclusiones de que ya alcanzaron la tercera región del aire, o sea la región del fuego donde se fabrican los relámpagos y los truenos. Sancho decide quitarse la venda que cubre sus ojos, cuando en ese momento ocurre una explosión, después de la cual los viajeros descubren que están aún en el lugar de donde partieron.

El Duque y la Duquesa siguieron con gran placer el diálogo de los viajeros durante su viaje $y$, al terminar éste, están ansiosos de saber por boca de ellos lo que experimentaron mientras montaban a Clavileño. Están exactamente en la posición de un psicólogo de nuestros días en el laboratorio, cuando experimenta con sus sujetos, usando el llamado fenómeno autocinestésico. El conocido psicólogo Muzafer Sherif, por ejemplo, dice a su sujeto que en el laboratorio oscuro una luz (la cual en verdad está físicamente inmóvil). se moverá hacia la izquierda o hacia la derecha, según el caso. Después el psicólogo verifica la respuesta que da el sujeto del experimento, $y$, finalmente, repite el mismo experimento con varios sujetos para observar la situación colectiva, en la cual cada sujeto da a conocer su juicio en voz alta, con lo que influye sobre los juicios que los otros dan y a la vez es influído por los juicios de los demás.

Sancho tiene que informar primero, y su relato parece un cuento de desenfrenada fantasía científica, al estilo de los que se producen en nuestros días. Asegura, entre otras cosas, que él y Don Quijote alcanzaron la constelación celestial de Capricornio y que él jugó durante una hora con "las siete cabrillas" de que está compuesta dicha constelación, mientras Clavileño le esperaba, 
etcétera. Pero Don Quijote estaba con él. Análogamente a lo que ocurre en el experimento del profesor Sherif, Don Quijote escuchó el cuento de Sancho. ¿Puede confirmarlo? El dice: "Como todas estas cosas y esos tales sucesos van fuera del orden natural, no es mucho que Sancho diga lo que dice. De mí sé decir que ni me descubrí por alto ni por bajo, ni vi el cielo, ni la tierra, ni la mar ni las arenas" (p. 552). Para poder alcanzar una constelación celestial tuvieron que pasar más allá de la región del fuego. Tal vez la tocaron, pero es increíble que la hayan atravesado. Esto no puede suceder sin abrasarse... "pues no nos asuramos”, Don Quijote concluye, “...o Sancho miente, o Sancho sueña".

Resulta interesante que Don Quijote, quien tiene plena conciencia de que toda la aventura está fuera del orden de la naturaleza, se refiera precisamente a este mismo orden natural para establecer las premisas de su conclusión perfectamente lógica. ¿Sería posible, acaso, que los magos que construyeron Clavileño les permitieran atravesar la región ígnea sin quemarse? Este es un punto muy importante: para poder explicar las contradicciones entre los dos sub-universos, tenemos que acudir a las reglas interpretativas con las cuales se constituye un tercer sub-universo, aunque sabemos muy bien que cada uno de los dos reinos está separado del otro y es irreductible al tercero. Pero Don Quijote todavía mantiene abierta la posibilidad de que Sancho hubiera sonado. Sabe, por su propia experiencia en la cueva de Montesinos, lo difícil que es establecer una línea divisoria entre realidad y ficción. Se acerca a Sancho y susurra en su oído: "Sancho, pues vos queréis que se os crea lo que habéis visto en el cielo, yo quiero que vos me creáis a mí lo que vi en la cueva de Montesinos" (p. 553).

Miguel de Unamuno, en su maravilloso comentario sobre Don Quijote, interpreta este juicio del caballero como una expresión de la más alta magnanimidad de su cándida alma, ya que Don Quijote está bien convencido de que lo sucedido en la cueva de Montesinos fué verdad y que lo que Sancho cuenta no puede serlo. Pero cabe otra interpretación. Don Quijote está convencido de que tan sólo el Yo experimentante es quien puede determinar cuál sea el sub-universo al que_el Yo ha conferido la dimensión de realidad. La experiencia intersubjetiva, la comunicación, la participación en algo común, presupone, en última instancia, una fe en la veracidad del otro; fe animal en el sentido de Santayana, la cual implica que yo doy por supuesta la posibilidad de que el otro otorgue la dimensión de realidad a uno de los innumerables sub-universos, y por otra parte, implica que él, el otro, da por supuesto que también yo tengo la facultad de determinar lo que es mi ensueño, lo que es mi fántasta y to que es mi vida real. Éste es el último análisis en la dialéctica intersubjetiva de fa realidad, $y$, por lo tanto, me parece a mí, la culminación en el estudio de este problema en la obra de Cervantes.

Es también el viraje en la tragedia personal de Don Quijote. Con la explo- 
sión de Clavileño -o mejor, con la imposibilidad de establecer intercomunicación en el sub-universo de la fantasía- pierde su poder mágico de autoencantamiento. Ante las mentiras de Sancho siente el desacato que cometió al entremezclar la realidad con la fantasía en el relato de sus aventuras en la cueva -los términos "realidad" y "fantasía" se emplean aquí desde el punto de vista de la realidad del mundo particular de Don Quijote-; siente que ha traspasado las fronteras que él mismo puso en la realidad de su reino particular, y que se ha permitido soñar dentro de sus límites, entremezclando, de tal suerte, dos reinos de realidad, y pecando en contra del espíritu de la verdad, siendo así que el defender este espíritu es la primera tarea del caballero andante. Al volver de la cueva de Montesinos, Don Quijote habló en términos parecidos a los de su hermano menor Segismundo, en La Vida es Sueño, de Calderón: "Dios os lo perdone, amigos; que me habéis quitado de la más sabrosa y agradable vida y vista que ningún humano ha visto ni pasado. En efecto, ahora acabo de conocer que todos los contentos desta vida pasan como sombra y sueño..." (p. 461).

Sin embargo, la experiencia trascendental de que la vida puede ser un sueño pone en cuestión no solamente la realidad del mundo del sentido común de la vida cotidiana, sino también la de cualquier otro sub-universo que se haya aceptado. La verdadera tragedia para Don Quijote es el descubrimiento de que, incluso su sub-universo privado, el reino de la caballería, puede ser sólo un ensueño, y de que sus placeres pasan como sombras. Esto crea, no solamente un conflicto en la conciencia psicológica, que se convierte, con palabras de Hegel, en "infeliz", sino también un conflicto en la conciencia moral, especialmente cuando la aventura de Clavileño prueba que incluso los Sanchos son capaces de entremezclar elementos de ensueños con la realidad de sus propias vidas cotidianas.

La intuición de Don Quijote, de que la intercomunicación se garantiza solamente por la fe mutua en los términos de la realidad del otro, y su exhortación a Sancho para que crea en sus visiones, si es que éste quiere que Don Quijote crea en las suyas, es una especie de déclaración de quiebra; las palabras finales en esta ocasión: "Y no os digo más", aumentan la tragedia de su mente y de su conciencia, ya tan infelices. Es su mala fe la que en los capítulos restantes lo lleva a su ruina y a la destrucción de su sub-universo. Don Quijote se da cuenta de la realidad de la vida cotidiana, y ningún encantador lo ayuda a transformarla. Se quiebra su capacidad para interpretar la realidad del sentido común en los términos de su universo privado. Mientras que el desencantamiento de Dulcinea falla, el suyo tiene completo éxito. El gran proceso de desilusión consiste en un alejamiento constante de la dimensión de realidad de su sub-universo privado, el mundo de la caballería. Este mundo - para volver a la observación de William James con que comenzó este estudio- chocó finalmente con las realidades de la vida cotidiana, de tal manera, que su mente 
tuvo que elegir con qué quedarse. Después de haber mantenido vigorosamente durante todas sus aventuras su elección original, después de haber desarrollado un sistema científico -o quizás una especie de teología- de las actividades mágicas de los encantadores, cuya misión es reconciliar los esquemas contradictorios de interpretación, Don Quijote pierde la fe en este principio fundamental de su metafísica y cosmografía. Al final se encuentra de regreso en un mundo al que no pertenece, encerrado en la realidad cotidiana como si fuera una prisión, y torturado por el carcelero más cruel: la razón del sentido común, que tiene conciencia de sus propios límites. La razón del sentido común niega o disimula la irrupción de lo trascendental en este mundo de la vida cotidiana; pero muestra su fuerza invencible en la experiencia que todos nosotros tenemos del hecho de que el mundo de la vida cotidiana con sus cosas y acontecimientos, sus conexiones causales de las leyes naturales, sus hechos e instituciones sociales, nos es impuesto, y de que solamente lo podemos entender y dominar en una medida muy limitada, mientras que el futuro permanece abierto, velado e incierto, y que nuestra única esperanza y guía es la creencia de que podremos arreglárnoslas con este mundo si para nuestros fines prácticos nos comportamos ccmo se comportan los demás, y aceptamos lo que los demás toman como algo incuestionable; todo eso presupone nuestra fe en que las cosas continuarán siendo lo que han sido hasta ahora y que todo lo que nuestra propia experiencia de ellas nos ha enseñado soportará también la prueba en el futuro. Cuando Don Quijote al haber perdido su caballería andante perdió también su misión celestial, tuvo que prepararse, después de su muerte espiritual, para su fin físico. Y así múere, no como Don Quiiote de la Mancha, sino como Alonso Quijano, el bueno, hombre que se considera a sí mismo en su sano juicio, libre de las sombras nebulosas de la ignorancia, con las que se le había oscurecido el juicio mientras habitó en la provincia de la fantasía (p. 707).

Sansón Carrasco en su epitafio dice de él que, aunque vivió como loco, murió como cuerdo. Pero des que la significación de la cordura y de la locura no dependen únicamente del sub-universo sólo, dentro del cual esos criterios son válidos? ¿Qué es necedad, qué es cordura en el universo entero que abarca la suma total de todos nuestros sub-universos?

"No hay sino encomendarnos a Dios, y dejar correr la suerte por donde mejor lo encaminare" (p. 124), dice Sancho, quien, a pesar de todas las tentaciones de lo trascendental, permanece profundamente arraigado a la herencia del sentido común.

New School for Social Research.

ALFREd SCHüTZ New York, Estados Unidos 